\title{
Assessment of man's thermal comfort in practice
}

\author{
P. O. FANGER
}

Laboratory of Heating and Air Conditioning, Technical University of Denmark, Building 402, DK 2800 Lyngby, Denmark

\begin{abstract}
Fanger, P. O. (1973). British Journal of Industrial Medicine, 30, 313-324. Assessment of man's thermal comfort in practice. A review is given of existing knowledge regarding the conditions for thermal comfort. Both physiological and environmental comfort conditions are discussed. Comfort criteria are shown diagrammatically, and their application is illustrated by numerous practical examples. Furthermore, the effect on the comfort conditions of age, adaptation, sex, seasonal and circadian rhythm, and unilateral heating or cooling of the body is discussed. The term 'climate monotony' is considered. A method is recommended for the evaluation of the quality of thermal environments in practice.
\end{abstract}

In its Constitution, the World Health Organization (WHO) defines health as 'a state of complete physical, mental and social well-being and not merely the absence of disease or infirmity'. The inclusion of man's well-being in the definition of health reflects the increasing interest which public health officers, hygienists, and many physicians have shown in man's comfort.

In this connection the indoor climate warrants special attention because in a modern industrial society man spends the greater part of his life indoors. A large proportion of the population spends 23 out of 24 hours in an artificial climate-in dwellings, at the workplace, at hobby, amusement, and cultural centres, or during transport by car, train, ship or aeroplane.

This has resulted in a growing understanding and interest in studying the influence of the indoor climate on man, thus enabling suitable requirements to be established, which should be aimed at in practice.

At the same time an increasing number of complaints about unsatisfactory indoor climate suggest that man has become more critical regarding the environment to which he is subjected. It seems that he is most inclined to complain about the indoor climate of his workplace (offices, industrial premises, shops, schools, etc.) where he is compelled to spend his time in environments which he himself can control only to a very limited degree.

Field studies indicate that in practice many of these complaints can be traced to an unsatisfactory thermal environment.

In this article the conditions for man's thermal comfort will be discussed, as well as the thermal environments which should be aimed at and the methods which should be employed in practice to evaluate the quality of a given thermal environment.

Only thermal environments which cause moderate degrees of discomfort will be dealt with. It is these cases that bring forth by far the greatest number of complaints met by physicians and engineers. Over recent years research has led to the establishment of rational methods for the assessment of such thermal environments.

Methods for determining the risk of thermal disorders when man is exposed to extreme thermal stress (i.e., during hard physical work in mines or in hot industry) will not be discussed here. Wellestablished and reliable methods have long been 
available for such cases, e.g., as reviewed in the monographs of Leithead and Lind (1964) and of Kerslake (1972).

\section{Comfort parameters}

What is required in practice is that the comfort conditions are expressed in controllable factors, namely the following four main physical parameters which constitute the thermal environment:

1. air temperature

2. mean radiant temperature

3. relative air velocity

4. vapour pressure in ambient air.

Besides the environmental factors, man's comfort is also influenced by the following two factors:

5. activity level (internal heat production in the body)

6. thermal resistance of clothing.

As suggested by Gagge, Burton, and Bazett (1941), activity is often expressed in met-units $\left(1 \mathrm{met}=58 \mathrm{~W} / \mathrm{m}^{2}\left(50 \mathrm{kcal} / \mathrm{m}^{2} \mathrm{~h}\right)\right.$ corresponding to sedentary activity) and the thermal resistance of the clothing is expressed in clo-units $\left(1 \mathrm{clo}=0.155 \mathrm{~m}^{2}\right.$ $\left.{ }^{\circ} \mathrm{C} / \mathrm{W}\left(0.18 \mathrm{~m}^{2} \mathrm{~h}{ }^{\circ} \mathrm{C} / \mathrm{kcal}\right)\right)$.

The activity and the thermal resistance of the clothing can be estimated with reasonable accuracy by considering the application of the room concerned. Values for typical activities and clothing ensembles are listed in Tables 1 and 2.

\section{TABLE 1}

Heat Production in the Body during Different TYPICAL ACTIVITIES

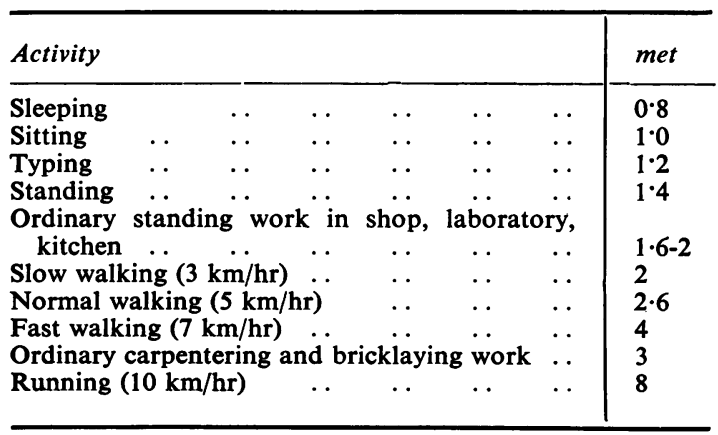

In practice, quantitative knowledge is needed as to which combinations of the above-mentioned six variables will lead to thermal comfort for man.

The existing knowledge of comfort conditions will be discussed, including the correlation between man's thermal sensation and his physiological reactions. But before proceeding to a discussion of comfort conditions it is important to define the concept of comfort.
TABLE 2

Thermal Resistance of Different Clothing ENSEMBLES

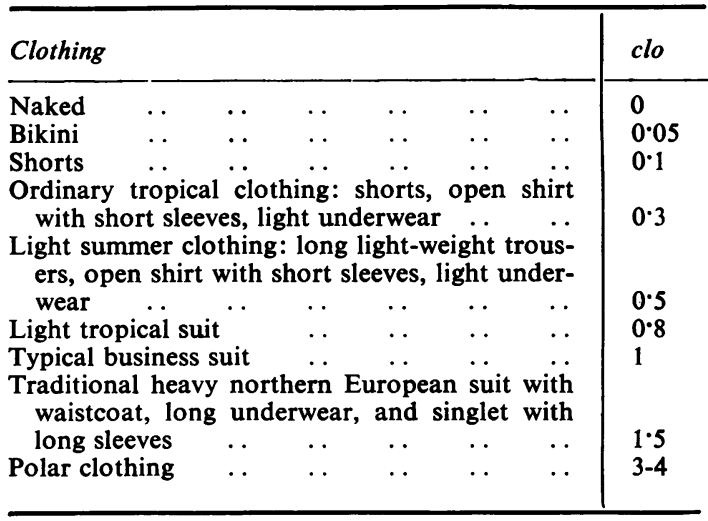

\section{Definition of comfort}

In agreement with the American Society of Heating, Refrigerating and Air-conditioning Engineers (ASHRAE) Standard 55-66 (1966), thermal comfort for a person is here defined as 'that condition of mind which expresses satisfaction with the thermal environment'. Normally this means that the person does not know whether he would prefer a warmer or a cooler environment. Furthermore, it is a requirement that the heat loss from the person is not too asymmetrical.

People are not alike, thermally or otherwise. If a group of people is exposed to the same room climate it will therefore normally not be possible, due to biological variance, to satisfy everyone at the same time. One must then aim at creating optimal thermal comfort for the group, i.e., a condition in which the highest possible percentage of the group are thermally comfortable.

\section{Physiological comfort conditions}

The purpose of the human thermoregulatory system is to maintain a reasonably constant deep body temperature; a requirement for this is the maintenance of a heat balance so that the heat lost to the environment is equal to the heat produced by the body. Man possesses the most effective physiological mechanisms for maintaining a heat balance: the sensible heat loss can be altered by a variation of the cutaneous blood flow and thus of the skin temperature, latent heat loss can be increased by sweat secretion, and internal heat production can be increased by shivering or muscle tension.

These mechanisms are extremely effective and ensure that the heat balance can be maintained within wide limits of the environmental variables. 
Maintenance of heat balance is, however, far from being a sufficient condition for thermal comfort. Within the wide limits of the environmental variables for which heat balance can be maintained there is only a narrow interval which will create thermal comfort.

It has long been known that man's thermal sensation is related to the state of his thermoregulatory system, the degree of discomfort being greater the heavier the load on the effector mechanisms. Experiments by Yaglou (1927) in the 1920s indicated a correlation between the skin temperature and the sensation of thermal comfort; later and more complete studies by Gagge, Herrington, and Winslow (1937), Gagge et al. (1941), Winslow, Herrington, and Gagge (1937), DuBois, Ebaugh, and Hardy (1952), and Nielsen (1947) showed a correlation between thermal sensation and skin temperature, independent of whether the subjects were nude or clothed. Therefore it was generally accepted for a long time that the physiological conditions for comfort were that a person had a mean skin temperature of $33-34^{\circ} \mathrm{C}$ and that sweating (or shivering) did not occur. This was later confirmed in experiments by Fanger (1967) but only for sedentary subjects. At higher activities than sedentary ones he showed that man prefers a lower mean skin temperature and prefers to sweat. Based on experimental results for 20 subjects each participating in four tests at different activity levels, and based on data by McNall et al. (1967), the following values of skin temperature and sweat secretion were found to provide comfort during steady-state conditions (Fanger, 1967):

Mean skin temperature during comfort:

$t_{s}=35.7-0.0276 \mathrm{M} \quad\left({ }^{\circ} \mathrm{C}\right)$

Sweat secretion during comfort:

$E_{\mathrm{sw}}=0.42(\mathrm{M}-58) \quad\left(\mathrm{W} / \mathrm{m}^{2}\right)$

where $M$ is the metabolic rate per unit body surface area $\left(\mathrm{W} / \mathrm{m}^{2}\right)$.

It is apparent from equation (1) that during sedentary activity $\left(M=58 \mathrm{~W} / \mathrm{m}^{2}\right)$ man prefers a skin temperature of approximately $34^{\circ} \mathrm{C}$, while the preferred skin temperature is, for example, only approximately $31^{\circ} \mathrm{C}$ at an activity three times that of the sedentary level.

From equation (2) it can be seen that man prefers a sweat secretion of zero during sedentary activity $\left(M=58 \mathrm{~W} / \mathrm{m}^{2}\right)$, whereas at higher activities he prefers a sweat secretion involving a latent heat loss of $42 \%$ of the increased heat production of the body. Ambient temperatures which were so low that no sweating occurred were felt to be much too cold.

It should be noted that a certain wetness of the skin in itself can produce a non-thermal discomfort due to tactile sensations associated with dripping wet clothing, sticky skin, and skin irritation. A high wet- ness of the skin can occur if the sweat secretion or the vapour diffusion resistance of the clothing are high. Gagge (1937), who introduced the 'skin wetness' concept, recommends that it should be lower than $25 \%$ (Gagge, Stolwijk, and Nishi, 1969a).

It must be emphasized that the physiological comfort conditions given in equations (1) and (2) apply only under reasonably steady-state conditions. It has not been possible as yet to establish physiological comfort conditions during thermal transients but important studies on transients have been performed at the Pierce Foundation Laboratory, Yale University, by Gagge, Stolwijk and Hardy (1967), Gagge, Stolwijk, and Saltin (1969b), Hardy and Stolwijk (1966), and Stolwijk and Hardy (1966). In one series of experiments nude subjects were exposed alternately to cold and neutral and to hot and neutral environments. When proceeding from neutral to cold or warm environments, the changing thermal sensation was found to be correlated with the actual skin temperature and sweat rate in the same way as under steady-state conditions. But when these transients were reversed, i.e., proceeding from a cold or hot to a neutral environment, they felt almost immediately comfortable, even though their skin temperature had not yet reached the steadystate level considered comfortable. Gagge explains this by the rate of change of skin temperature which might cause a sensation that compensates for and predominates over the sensation of discomfort caused by the skin temperature itself. The thermal sensation 'leads' the body temperature changes in this case and is thus 'anticipatory'.

Other transient experiments by Cabanac (1969, 1971) and by Hardy (1970) with subjects immersed in a waterbath indicate that an interaction of internal and skin temperature might be important in evoking discomfort. The possible influence of internal temperature has also been suggested by Missenard (1957).

The relationship between man's thermal sensation and his physiological reactions during sudden environmental changes is certainly complicated, and further research is necessary before it will be possible to establish quantitative physiological comfort conditions for thermal transients.

\section{Environmental comfort conditions}

When, in practice, artificial climates are to be created which will provide thermal comfort for man, it is of course insufficient merely to know the physiological comfort conditions. What is necessary is a detailed quantitative knowledge of those combinations of the environmental variables which will result in optimal thermal comfort.

Two research methods which differ in principle 
have been used to establish environmental comfort conditions, but both require a large number of subjects in order that the optimal condition can be stated with reasonable statistical certainty.

In one of the methods the subjects are asked to vote on their thermal sensation on suitable psychophysical scales, and at the same time measurements are taken of the ambient thermal climate to which they are exposed. Subsequently the results are treated statistically and the optimal thermal environment can be determined.

This method is relatively simple and has therefore been used in a large number of field studies in all parts of the world. The best known study of this nature is Bedford's (1936) classical study on factory workers, but recent investigations by Wyon, Lidwell, and Williams (1968), and Humphreys and Nicol (1970) have used the same method.

In many field studies activity level, and especially clothing, have not been specified, and in some cases it has not been possible to measure all the environmental variables. Even though the results of such field studies have often been of value in the actual conditions under which they were measured, it is difficult to make generalisations from the results and to apply them to other conditions.

The same method has been used in recent years in extensive experimental studies under carefully controlled laboratory conditions at Kansas State University by Nevins, Rohles, Springer, and Feyerherm (1966), McNall et al. (1967), McNall, Ryan, and Jaax (1968), McNall and Schlegel (1968), Rohles and Nevins (1971), Rohles and Johnson (1972), and Rohles, Woods, and Nevins (1973). These experiments have involved many hundreds of subjects, who, clothed in a standard clothing ensemble, have been exposed to different combinations of two environmental variables (e.g., air temperature and relative humidity) while keeping constant, in so far as it is practically possible, all other factors which influence thermal comfort. Large numbers of subjects have been asked to vote upon their thermal sensation according to special scales. From a statistical analysis combinations of the two variables which give optimal thermal comfort have then been determined.

Because of the large number of subjects and the carefully controlled experimental conditions this method has given valuable results; however, these results are valid only for the constant values of the other four parameters prevailing when the experiments were performed. Since the effect of any of the six main parameters on man's thermal comfort depends on the level of the other parameters this empirical method requires an enormous number of experiments to cover the range adequately. The method is thus slow, and existing data therefore do not provide sufficient information for an overall assessment and calculation of the relative and absolute influence of all the individual variables on man's thermal comfort.

The other method for establishing environmental comfort conditions was employed by Fanger (1967) in the derivation of his comfort equation.

An underlying idea, later experimentally supported by Olesen, Bassing, and Fanger (1972a), is that it is the combined thermal effect of all the physical factors which is of importance for man's thermal state and comfort. It is therefore impossible to consider the effect of any of the physical factors influencing thermal comfort independently, as the effect of each of them depends on the level of the other factors.

The equation was derived by setting up a heat balance equation for the human body and inserting in it the physiological comfort conditions for skin temperature and sweat secretion given in equations (1) and (2). In this way, the comfort equation establishes those combinations of activity, clothing, and the four environmental variables which will provide thermal comfort. It has been known for a long time that these six variables influence the state of comfort. But the combined quantitative influence of all the parameters on man's comfort was not known until the equation was introduced.

\section{Practical application of comfort diagrams}

The comfort equation is comprehensive and complex and therefore unsuitable for manual calculation, but it has been solved by the use of electronic data processing and has been plotted in 28 comfort diagrams (Fanger, 1970); these diagrams are intended for use in practice. In Figs. 1 to 4, examples are shown of four of the comfort diagrams. In each diagram comfort lines have been drawn, i.e., curves through various combinations of two variables which will create comfort providing the values of the other variables are kept constant.

For practical application of the comfort diagrams, it is necessary to estimate the activity level and the clothing first, taking into account the use of the room (see Tables 1 and 2). From the comfort diagrams, combinations can then be found of the four environmental parameters which will provide thermal comfort.

Beneath Figs. 1 to 4 nine characteristic examples are given of the use of the comfort diagrams in practice.

\section{Individual differences}

Everyone is not alike. How then is it possible, from an equation, to specify one particular temperature which will provide comfort? The answer is that the 
comfort equation does not necessarily satisfy everyone. It gives, however, combinations of the variables which will provide comfort for the greatest number of people. This is exactly what should be aimed at when a large group of people are together in the same room climate (optimal comfort for the group).

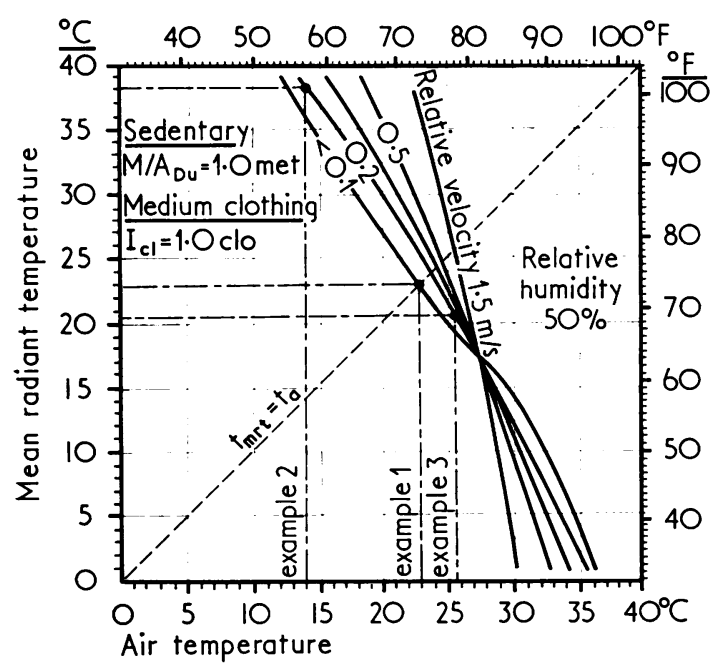

FIG. 1. Comfort diagram showing the combined influence of mean radiant temperature and air temperature. The comfort lines corresponding to five different velocities are curves through different combinations of mean radiant temperature and air temperature which will provide optimal thermal comfort. The diagram applies for sedentary persons in medium clothing $(0 \cdot 1$ clo). Relative humidity $50 \%$. The slope of the lines has been reasonably well confirmed by recent British studies (Griffiths and McIntyre, 1972a).

Example 1 In an office, the employees are clothed at 1 clo (normal business suit) and occupied with sedentary work (1 met). Relative humidity $50 \%$, relative air velocity $<0.1 \mathrm{~m} / \mathrm{s}$. It is desired to determine the optimal air temperature, presuming that the mean radiant temperature $=$ the air temperature. From Fig. 1, $\mathrm{t}_{\mathrm{a}}=\mathrm{t}_{\mathrm{mrt}}=23.0^{\circ} \mathrm{C}$ is found.

Example 2 In a warehouse an air temperature of $14^{\circ} \mathrm{C}$ and a relative humidity of $50 \%$ should be maintained owing to the nature of the goods. Air velocity is $0.2 \mathrm{~m} / \mathrm{s}$. In the warehouse, a person is occupied with sedentary work, clothed at 1 clo. It is desired to maintain the person in comfort by means of high-intensity infrared heaters placed above his workplace. The mean radiant temperature necessary for comfort is to be calculated. From Fig. $1, \mathrm{t}_{\mathrm{mrt}}=38^{\circ} \mathrm{C}$ is found.

Example 3 Under winter conditions the mean radiant temperature in a long-distance bus is calculated to be $5^{\circ}$ lower than the air temperature. It is desired to determine the air temperature necessary for comfort, the passengers being presumed to be seated without top clothes $(1.0 \mathrm{clo})$ and the velocity being $0.2 \mathrm{~m} / \mathrm{s}$ (relative humidity $50 \%$ ). From Fig. 1: $\mathrm{t}_{\mathrm{a}}=25 \cdot 5^{\circ} \mathrm{C}$ and $\mathrm{t}_{\mathrm{mrt}}=$ $20 \cdot 5^{\circ} \mathrm{C}$.

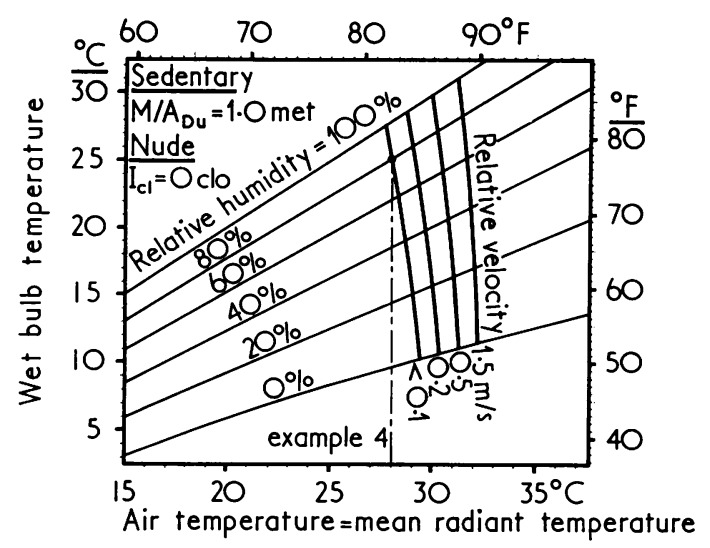

FIG. 2. Comfort diagram showing the combined influence of humidity and ambient temperature. The comfort lines corresponding to four different velocities are curves through different combinations of ambient temperature and humidity which will provide optimal thermal comfort. The diagram applies for nude, sedentary persons.

Example 4 At swimming baths with rest places it is desired to establish the necessary air temperature which will maintain thermal comfort for sedentary nude persons. Relative air humidity is $80 \%$, relative air velocity $<0.1 \mathrm{~m} / \mathrm{s}$, and air temperature = mean radiant temperature. From Fig. 2, $\mathrm{t}_{\mathrm{a}}=28 \cdot 0 \mathrm{C}$ is found.

It has been found from experiments involving 1300 subjects that the best result attainable is $5 \%$ dissatisfied (Fanger, 1970). Any deviation from the thermal conditions specified by the comfort equation will result in an increase in the percentage of dissatisfied.

\section{Comfort zones or comfort points}

Earlier it was quite common to recommend so-called 'comfort zones'. How can it then be that for set values of the parameters the comfort equation establishes only one comfort temperature and not a comfort zone? It is true that for every person there exists an interval of ambient temperatures within which he will feel reasonably comfortable. Thus for each individual there exists a comfort zone. But as the comfort zone varies from person to person there will be no common interval of temperatures for a large group of persons which will satisfy them all. There will not even be one common temperature which will provide comfort for all. But, as mentioned earlier, there will be one ambient temperature at which the least possible number of persons will be dissatisfied $(5 \%)$. This 'comfort point' is established by the comfort equation.

\section{Variability in man's comfort conditions from day to day}

How reproducible are the comfort conditions for the 


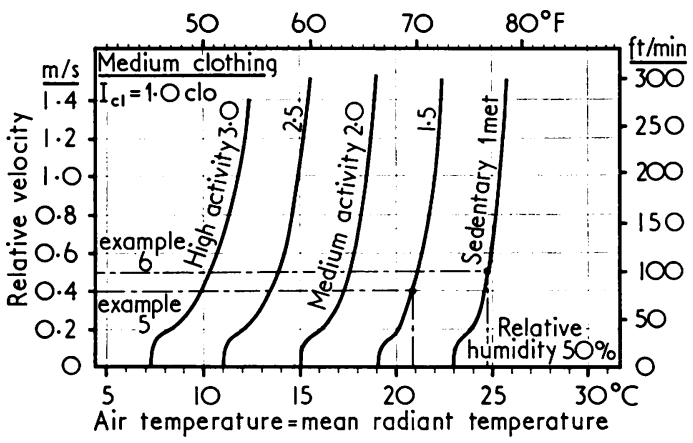

FIG. 3. Comfort diagram showing the combined influence of air velocity and ambient temperature. The comfort lines corresponding to five different activity levels are curves through different combinations of relative air velocity and ambient temperature which will provide optimal thermal comfort. The diagram applies for persons wearing medium clothing $(1.0$ clo $)$. Relative humidity $50 \%$.

Example 5 It is desired to determine the comfort temperature for the personnel in a shop, where the mean activity corresponds to walking at a speed of $1.5 \mathrm{~km} / \mathrm{hr}$ (activity $=1.5$ met, relative velocity $=0.4 \mathrm{~m} / \mathrm{s}$ ); clothing $=1.0$ clo, relative humidity $50 \%$. From Fig. 3 it will be seen that $\mathrm{t}_{\mathrm{a}}=\mathrm{t}_{\mathrm{mrt}}=20 \cdot 8^{\circ} \mathrm{C}$.

Example 6 In a 'clean room' (laminar flow type) the horizontal air velocity is $0.5 \mathrm{~m} / \mathrm{s}$ and the personnel are engaged in sedentary work clothed in a special standard suit $(1.0$ clo). Relative humidity $50 \%$. From Fig. 3 it will be seen that the comfort temperature is $24 \cdot 7^{\circ} \mathrm{C}$.

individual? Is not the subjective thermal sensation so uncertain that large variations in comfort requirements can be expected from day to day? This has recently been investigated by determining the preferred ambient temperature for each subject under identical conditions on four different days (Fanger, 1973). A standard deviation of only $0.6^{\circ} \mathrm{C}$ was found.

It is concluded that the comfort conditions for the individual can be reproduced and will vary only slightly from day to day.

\section{Age}

It has often been claimed that due to the fact that metabolism decreases slightly with age the comfort conditions based on experiments with young and healthy subjects cannot be used as a matter of course for other age groups. In Table 3 the results are summarized of recent comfort studies in Denmark and the United States of America on different age groups (mean age 21-84 years). Activity, clothing, and other experimental conditions have in all studies been identical. Subjects during one experi- ment are seen in Figure 5. It will be seen from Table 3 that the thermal environments preferred by the elderly do not appear to differ from those preferred by younger people. The lower metabolism in elderly people seems to be compensated for by a lower evaporative loss.

The fact that young and elderly prefer the same thermal environment does not necessarily mean that they are equally sensitive when exposed to cold (or heat). This has recently been discussed by Fox et al. (1973) in relation to the hypothermia problem for the elderly.

\section{Adaptation}

It is widely believed that, by exposure to hot or cold surroundings, people can acclimatize themselves so that they prefer other thermal environments, and

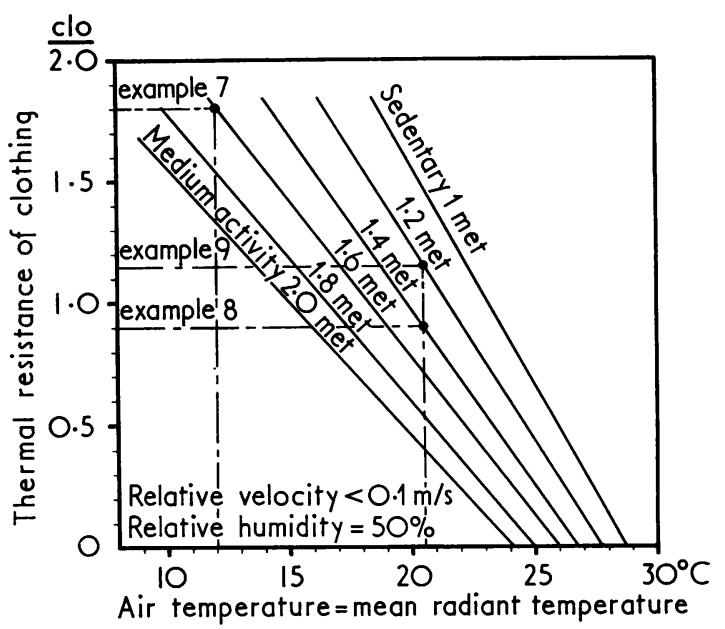

FIG. 4. Comfort diagram showing the combined influence of clothing and activity. The comfort lines corresponding to six different activity levels are curves through different combinations of clo-value and ambient temperature which will provide thermal comfort. Relative humidity is $50 \%$, relative air velocity $<0.1 \mathrm{~m} / \mathrm{s}$.

Example 7 A special uniform is to be made for personnel in the meat-packing industry who are employed in an environment of $12^{\circ} \mathrm{C}$. The necessary clo-value of the uniform must be determined, the activity level being set at 1.6 met. From Fig. 4 it can be seen that 1.8 clo corresponds to the desired conditions.

Example 8 In an operating theatre the surgeon is clothed at 0.9 clo and has an activity level of 1.4 met. It is desired to determine the ambient temperature (air temperature $=$ mean radiant temperature) which will provide thermal comfort. From Fig. $4, \mathrm{t}_{\mathrm{a}}=20 \cdot 5^{\circ} \mathrm{C}$ is found.

Example 9 In the same operating theatre, the other members of the operating team are engaged at a lower activity level (1.2 met). It must be determined what clovalue their standard clothing should have in order to provide thermal comfort. From Fig. 4, 1.15 clo is found. 
TABLE 3

Comparison between Comfort Conditions for Different Age Groups

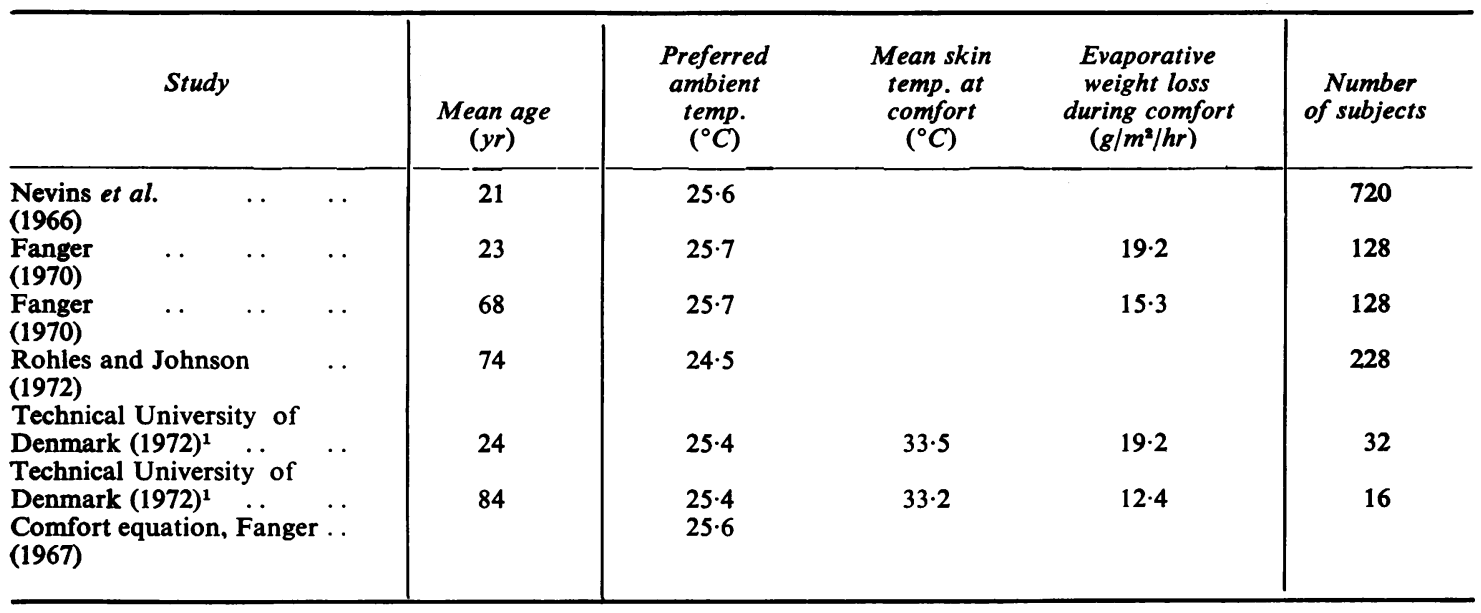

${ }^{1}$ Data not yet published

Subjects were tested under the following standardized conditions: sedentary activity, light standard clothing 0.6 clo, rel. velocity $<0.1 \mathrm{~m} / \mathrm{s}$, rel. humidity $50 \%$, mean radiant temperature $=$ air temperature.

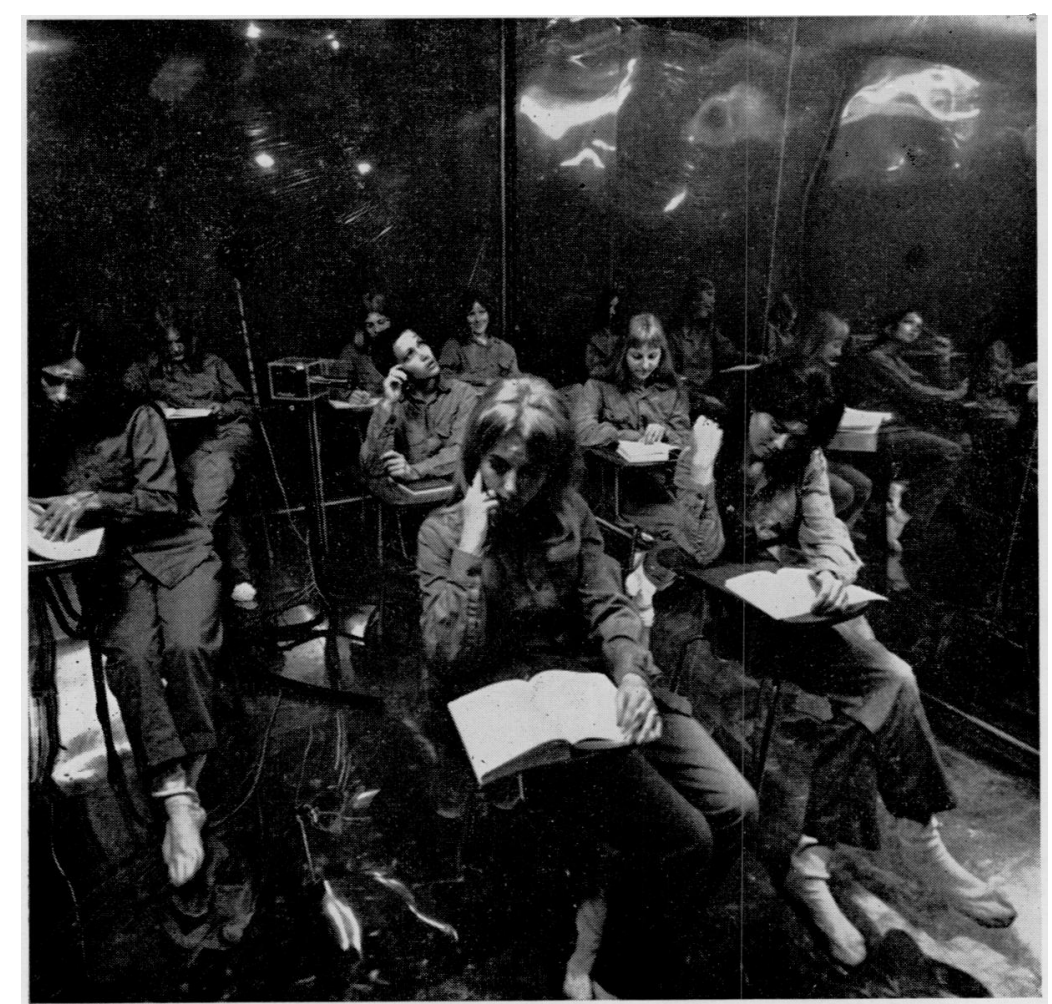

FIG. 5. Subjects wearing a standard uniform $(0.6 \mathrm{clo})$ during thermal studies in the environmental test chamber at the Technical University of Denmark. During the studies, physical and physiological measurements are correlated with the subjective evaluations of the subjects. 
that the comfort conditions vary in different parts of the world, depending on the outdoor climate at the relevant place. In Table 4 the results are shown of experiments (identical experimental conditions) involving subjects from the United States of America, Denmark, and tropical countries. The latter group was tested in Copenhagen immediately after their arrival by plane from the tropics where they had lived all their lives.

Moreover, Table 4 gives experimental results for two groups of persons exposed daily to cold. One group comprises persons who for eight hours daily for at least one year have been doing sedentary work in cold surroundings in the meat packing industry. The other group consists of winter swimmers who bathe daily in the sea.

It is apparent from the Table that there are only slight differences between the various groups as regards both the preferred ambient temperature and the physiological parameters in the comfort condition. The results indicate that man cannot become adapted to prefer warmer or colder environments.

It is therefore likely that the same comfort conditions can be applied throughout the world. However, in determining the preferred ambient temperature from the comfort diagrams, a clo-value should be used which corresponds to the local clothing habits. A comparison of field comfort studies from different parts of the world (Nicol and Humphreys, 1972) shows, as might be expected, significant differences in clothing habits depending, among other things, on the outdoor climate.

\section{Sex}

In all the experiments mentioned in Tables 3 and 4, an equal number of male and female subjects participated, and it is therefore possible to compare the comfort conditions for the two sexes (Table 5). It is shown that men and women seem to prefer almost the same thermal environments. Women's skin temperature and evaporative loss are slightly lower than those for men, and this balances the somewhat lower metabolism of women.

\section{Seasonal and circadian rhythm}

As it has been ascertained above that man cannot become adapted to prefer warmer or colder environments, it follows that there is no difference between comfort conditions in winter and in summer. This is confirmed by an investigation undertaken at Kansas State University where results of winter and summer experiments showed no difference (McNall et al., 1968).

On the other hand, it is reasonable to expect the comfort conditions to alter during the day as the internal body temperature has a daily rhythm, a maximum occurring late in the afternoon and a minimum early in the morning.

We have recently studied this by determining experimentally the preferred ambient temperature for each of 16 subjects both in the morning and in the evening. No difference was observed (Östberg and Nicholl, 1973). We have furthermore studied

TABLE 4

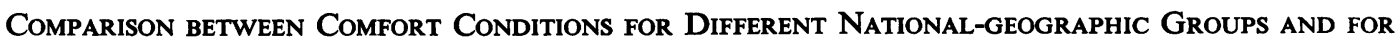
Groups of People Regularly Exposed to Extreme Cold or Heat

\begin{tabular}{|c|c|c|c|c|c|c|c|c|}
\hline \multicolumn{4}{|c|}{ Group } & Study & $\begin{array}{c}\text { Preferred } \\
\text { ambient } \\
\text { temp. } \\
\left({ }^{\circ} \mathrm{C}\right)\end{array}$ & $\begin{array}{l}\text { Mean skin } \\
\text { temp. } \\
\text { at comfort } \\
\left({ }^{\circ} \mathrm{C}\right)\end{array}$ & $\begin{array}{c}\text { Evaporative } \\
\text { weight loss } \\
\text { during comfort } \\
\left(\mathrm{g} / \mathrm{m}^{2} / \mathrm{hr}\right)\end{array}$ & $\begin{array}{c}\text { Number } \\
\text { of } \\
\text { subjects }\end{array}$ \\
\hline Americans & . & . & $\ldots$ & $\begin{array}{l}\text { Nevins et al } \\
\text { (1966) }\end{array}$ & $25 \cdot 6$ & & & 720 \\
\hline Danes & . & . & $\ldots$ & $\begin{array}{l}\text { Fanger } \\
(1970)\end{array}$ & $25 \cdot 7$ & & & 256 \\
\hline Danes & . & . & $\ldots$ & $\begin{array}{l}\text { Technical University of } \\
\text { Denmark }(1972)^{1}\end{array}$ & $25 \cdot 4$ & $33 \cdot 5$ & $19 \cdot 2$ & 32 \\
\hline People from & the tro & pics & $\ldots$ & $\begin{array}{l}\text { Technical University of } \\
\text { Denmark }(1972)^{1}\end{array}$ & $26 \cdot 2$ & $33 \cdot 5$ & $17 \cdot 1$ & 16 \\
\hline $\begin{array}{l}\text { Danes work } \\
\text { meat-pack }\end{array}$ & $\begin{array}{l}\text { sing in } \\
\text { sing ind }\end{array}$ & $\begin{array}{l}\text { the co } \\
\text { lustry }\end{array}$ & $\begin{array}{c}\text { old } \\
\ldots\end{array}$ & $\begin{array}{l}\text { Olesen and Fanger } \\
\text { (1971) }\end{array}$ & $24 \cdot 7$ & $33 \cdot 6$ & $17 \cdot 1$ & 16 \\
\hline & er swim & amers & $\ldots$ & $\begin{array}{l}\text { Technical University of } \\
\text { Denmark }(1972)^{1}\end{array}$ & $25 \cdot 0$ & $33 \cdot 3$ & $16 \cdot 6$ & 16 \\
\hline Comfort equ & lation & & $\ldots$ & $\begin{array}{l}\text { Fanger } \\
\text { (1967) }\end{array}$ & $25 \cdot 6$ & & & \\
\hline
\end{tabular}

${ }^{1}$ Data not yet published

Subjects were tested under the following standardized conditions: Sedentary activity, light standard clothing 0.6 clo, rel. velocity $<0.1 \mathrm{~m} / \mathrm{s}$, rel. humidity $50 \%$, mean radiant temperature = air temperature. 
TABLE 5

Comparison between Comfort Conditions for Males and Females

\begin{tabular}{|c|c|c|c|c|c|}
\hline Study & Sex & $\begin{array}{l}\text { Preferred } \\
\text { ambient } \\
\text { temp. } \\
\left({ }^{\circ} \mathrm{C}\right)\end{array}$ & $\begin{array}{l}\text { Mean skin } \\
\text { temp. } \\
\text { at comfort } \\
\left({ }^{\circ} \mathrm{C}\right)\end{array}$ & $\begin{array}{l}\text { Evaporative } \\
\text { weight loss } \\
\text { during comfort } \\
\left(\mathrm{g} / \mathrm{m}^{2} / \mathrm{hr}\right)\end{array}$ & $\begin{array}{c}\text { Number } \\
\text { of } \\
\text { subjects }\end{array}$ \\
\hline $\begin{array}{l}\text { Nevins et al. }(1966) \text { and } \\
\text { Fanger }(1970) \quad \ldots \\
\text { (both studies combined) }\end{array}$ & $\begin{array}{l}\text { Males } \\
\text { Femalics }\end{array}$ & $\begin{array}{l}25 \cdot 4 \\
25 \cdot 8\end{array}$ & & & $\begin{array}{l}488 \\
488\end{array}$ \\
\hline $\begin{array}{l}\text { Technical University of } \\
\text { Denmark }(1972)^{1}\end{array}$ & $\begin{array}{l}\text { Males } \\
\text { Females }\end{array}$ & $\begin{array}{l}25 \cdot 5 \\
25 \cdot 3\end{array}$ & $\begin{array}{l}33 \cdot 6 \\
33 \cdot 4\end{array}$ & $\begin{array}{l}21 \cdot 3 \\
17 \cdot 1\end{array}$ & $\begin{array}{l}16 \\
16\end{array}$ \\
\hline $\begin{array}{l}\text { Comfort equation } \\
\text { Fanger (1967) }\end{array}$ & & $25 \cdot 6$ & & & \\
\hline
\end{tabular}

${ }^{1}$ Data not yet published

Subjects were tested under the following standardized conditions: Sedentary activity: light standard clothing 0.6 clo, rel. velocity $<0 \cdot 1 \mathrm{~m} / \mathrm{s}$, rel. humidity $50 \%$, mean radiant temperature $=$ air temperature.

the preferred ambient temperature during a simulated eight-hour working day (sedentary work) (Fanger, Højbjerre, and Thomsen, 1973). It will be seen from Fig. 6 that we observed only small fluctuations in the preferred ambient temperature during the day. There is a slight tendency to prefer somewhat warmer surroundings before lunch, but none of the fluctuations is significant. It is recommended, therefore, that the thermal environment be kept constant throughout the day at a level given by the comfort equation.

\section{Climate monotony}

It has sometimes been claimed that a constant thermal environment is not ideal as it produces socalled climate monotony-increased fatigue, lower arousal, lower performance, etc. But such claims have not so far been supported by experimental evidence.

We have recently performed a preliminary study of this problem by exposing subjects to temperature swings of varying amplitudes and frequencies around the comfort level (Wyon, Asgeirsdóttir, KjerulfJensen, and Fanger, 1973). At the same time their thermal sensations, mental performance, and behaviour were studied. Slight positive effects on performance were observed but only with large temperature swings which were felt to be definitely uncomfortable. More comprehensive studies are needed. Until then I would recommend keeping ambient temperatures constant at the level given by the comfort diagrams.

\section{Unilateral heating or cooling of the body}

Although a person may feel thermally neutral for the body in general, i.e., he would prefer neither a warmer nor a cooler environment, he might not be in thermal

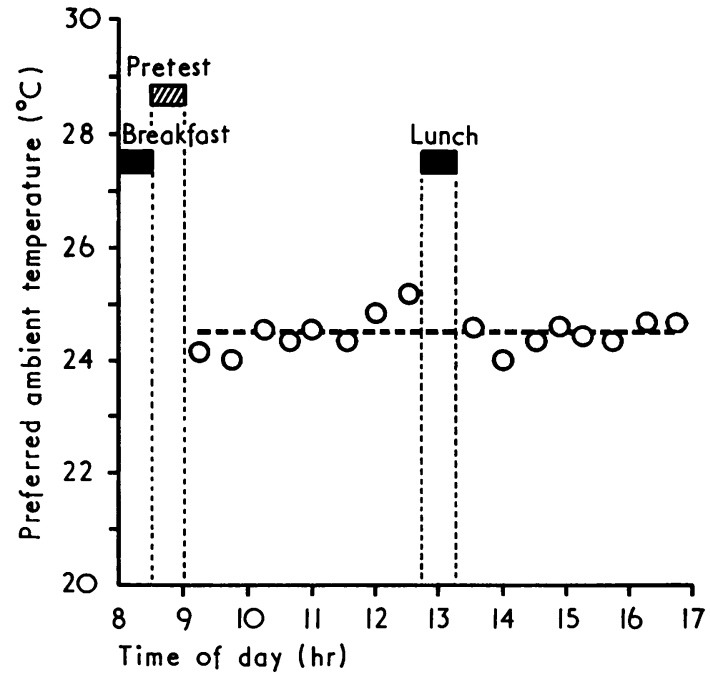

FIG. 6. Mean of the preferred ambient temperature for 16 subjects during a simulated normal 8-hour working day. Sedentary activity, light standard clothing 0.6 clo, relative air velocity $<0.1 \mathrm{~m} / \mathrm{s}$, relative humidity $50 \%$, mean radiant temperature $=$ air temperature (Fanger, 1973).

comfort if one part of the body is warm and another is cold. This might be caused by an asymmetric radiant field or a local convective cooling of the body (draught) or by contact with a warm or cool floor. Besides the comfort conditions for the body in general, it is therefore essential to establish limits for how asymmetric the heat loss from the body can be without evoking discomfort.

Limits for asymmetric radiation were recently studied experimentally by Olesen, Fanger, Jensen, and Nielsen (1972b). The following formula for 
estimating the limits of acceptable temperature differences of a local radiant source for sedentary persons in thermally neutral environments with still air was recommended:

$$
-2 \cdot 4-1 \cdot 8 \mathrm{I}_{\mathrm{cl}} \leqq \Delta \mathrm{t}_{\mathrm{w}} \mathrm{F}_{\mathrm{p}-\mathrm{w}} \leqq 3.9+1.8 \mathrm{I}_{\mathrm{cl}}
$$

where $\mathrm{I}_{\mathrm{cl}}=$ clo-value of clothing

$F_{p-w}=$ angle factor between person and radiant source

$\Delta \mathrm{t}_{\mathrm{w}}=$ temperature difference $\left({ }^{\circ} \mathrm{C}\right)$ between radiant source and mean radiant temperature in relation to the person.

This formula is in reasonable agreement with other recent data by McNall and Biddison (1970) and by Griffiths and McIntyre (1972b), while Chrenko (1953) 20 years ago established more conservative limits for hot ceilings.

Local convective cooling is a considerable problem in practice and unfortunately it has been only superficially investigated so far. The mean air velocity and the air temperature are, of course, of importance for convective heat transfer and they should be balanced according to the comfort equation. But the mean velocity is not sufficient to explain the draught phenomenon. Man can be comfortable at quite substantial air velocities (i.e., $1 \mathrm{~m} / \mathrm{s}$ ) provided that the ambient temperature is adjusted to a suitable level; but in other cases a mean velocity of $0.3 \mathrm{~m} / \mathrm{s}$ might evoke a sensation of draught. Other aerodynamic magnitudes might be important and preliminary experiments at the Technical University of Denmark indicate that the turbulence of the air is a significant factor for the sensation of draught. More studies are needed in order to establish reliable draught limits.

\section{Practical assessment of thermal environments}

When evaluating the thermal climate of a room in practice, the thermal parameters must first be measured at a suitable number of points in the occupied zone. Deviations from the optimal condition given in the comfort diagrams can then be determined.

However, it is often of value to quantify the degree of discomfort, and for this purpose an index has been devised which gives the predicted mean vote (PMV) of a large group of subjects according to the following psychophysical scale:

$$
\begin{array}{ll}
-3 & \text { cold } \\
-2 & \text { cool } \\
-1 & \text { slightly cool } \\
0 & \text { neutral } \\
+1 & \text { slightly warm } \\
+2 & \text { warm } \\
+3 & \text { hot }
\end{array}
$$

The PMV value is determined from tables (Fanger, 1970) and it is then possible, from Fig. 7, to determine the predicted percentage of dissatisfied (PPD).

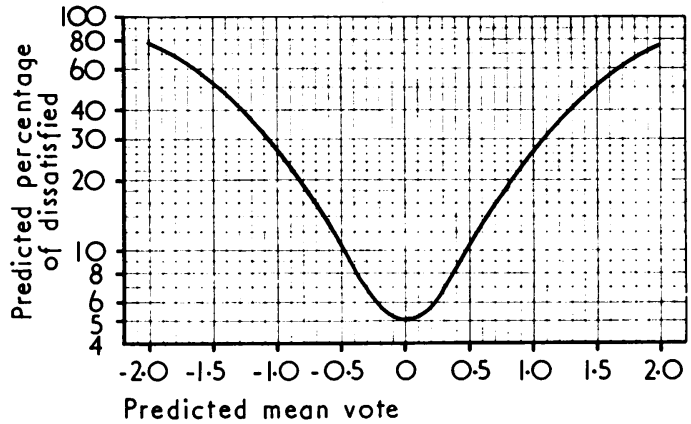

FIG. 7. The predicted percentage of dissatisfied (PPD) as a function of the predicted mean vote (PMV). The curve has a minimum value of $5 \%$ dissatisfied persons for $\mathrm{PMV}=0$. This corresponds to optimal thermal comfort. The curve is based on experiments comprising 1300 subjects (Fanger, 1970).

Figure 7 is based on studies comprising 1300 experimental subjects. As mentioned earlier, $5 \%$ is the lowest percentage of dissatisfied which can be expected. The PPD value is an appropriate and easily understood expression for the quality of a given thermal environment.

An instrument which measures simultaneously the PMV and PPD values has recently been developed by Korsgaard and Madsen $(1971,1973)$. It has a sensor which integrates the comfort parameters in the same way as the human body does (Fig. 8). Experience from practice has shown this instrument to be a reliable and useful tool in assessing thermal environments in the field.

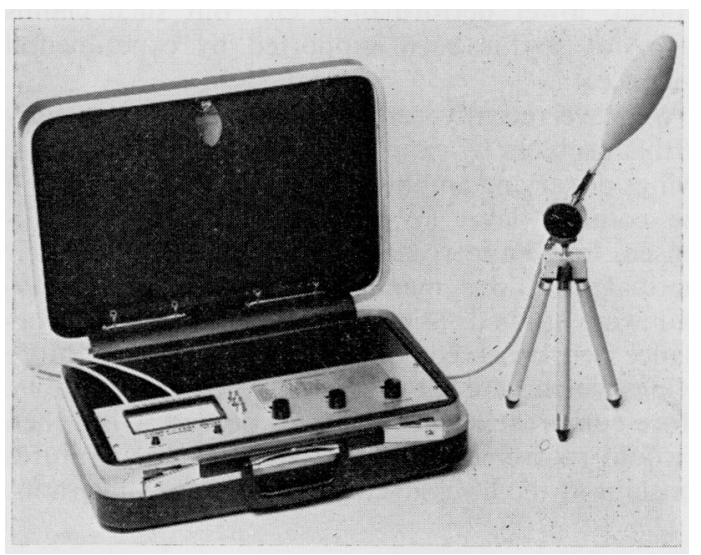

FIG. 8. Comfort-meter developed by Korsgaard and Madsen $(1971,1973)$. The sensor integrates the influence of the thermal parameters in the same way as the human body (Comfy-test EQ-21, commercially available from RECI, Glosemosevej, 2600 Glostrup, Denmark). 


\section{Future research}

Conclusive new evidence has come to light on man's comfort conditions as a result of extensive research carried out during recent years. This knowledge is quantified so that it is directly applicable in practice. However, several problems still exist which demand our efforts in this field of research in the future.

It is partly a matter of establishing comfort conditions during transients (including temperature and humidity fluctuations and sudden changes, for instance, when a person moves from outdoors to indoors). In this connection it would be appropriate to perform more fundamental studies to clarify the correlation between man's thermal sensation and the function of his thermoregulatory system.

Comfort studies on children are needed to investigate whether the comfort conditions for adults apply also to this age group.

There is also a need for further studies on the effect on man of unilateral heating or cooling of the body. The correlation between the sensation of draught and the turbulence intensity of the air should be studied. Comfort limits should be established for the floor temperature as a function of floor material and footwear.

More studies are needed on the thermal properties of clothing ensembles and on the connection between clothing habits and behavioural temperature regulation.

Another problem which has hardly been investigated at all is the possible influence of non-thermal environmental factors on man's thermal sensation. Even though an influence from, e.g., light (colour) or sound on man's thermal sensation has not yet been found, the possibility of the existence of such a pure psychological influence cannot be excluded, and an experimental investigation of the problem would therefore seem to be relevant.

Furthermore, there is a need for studies of comfort conditions for sleeping persons. The investigation and establishment of optimal thermal conditions for sleep is of great practical significance for the planning and operating of heating and air-conditioning systems for hotels and hospitals.

\section{References}

American Society of Heating, Refrigerating and Air-Conditioning Engineers (1966). Thermal comfort conditions. ASHRAE Standard 55-66, New York.

Bedford, T. (1936). The warmth factor in comfort at work. Reports of the Industrial Health Research Board, No. 76, London.

Cabanac, M. (1969). Plaisir ou déplaisir de la sensation thermique et homeothermie. Physiology and Behavior, 4, 359-364.

- (1971). Physiological role of pleasure. Science, 173, 1103-1107.

Chrenko, F. A. (1953). Heated ceilings and comfort. Journal of the Institute of Heating and Ventilating Engineers, 20, 375-396; 21, 145-154.
DuBois, E. F., Ebaugh, F. G., and Hardy, J. D. (1952). Basal heat production and elimination of thirteen normal women at temperatures from $22^{\circ} \mathrm{C}$ to $35^{\circ} \mathrm{C}$. Journal of Nutrition, 48, 257-293.

Fanger, P. O. (1967). Calculation of thermal comfort: Introduction of a basic comfort equation. $A S H R A E$ Transactions, 73. Part II, pp.III. 4.1-III, 4.20(No. 2051). (1970). Thermal Comfort. Danish Technical Press, Copenhagen. Republished by McGraw-Hill Book Co., New York, 1973.

(1973). The variability of man's preferred ambient temperature from day to day. Proceedings of symposium on "Quantitative prediction of the physiological and psychological effects of the thermal environment on man", Centre d'Etudes Bioclimatiques, Strasbourg, July.

_- Højbjerre, J., and Thomsen, J. O. B. (1973). Man's preferred ambient temperature during the day. Proceedings of symposium on "Quantitative prediction of the physiological and psychological effects of the thermal environment on man", Centre d'Etudes Bioclimatiques, Strasbourg, July.

Fox, R. H., Woodward, Patricia M., Exton-Smith, A. N., Green, M. F., Donnison, D. V., and Wicks, M. H. (1973). Body temperatures in the elderly: A national study of physiological, social, and environmental conditions. British Medical Journal, 1, 200-206.

Gagge, A. P. (1937). A new physiological variable associated with sensible and insensible perspiration. American Journal of Physiology, 120, 277-287.

- Burton, A. C., and Bazett, H. C. (1941). A practical system of units for the description of the heat exchange of man with his environment. Science, 94, 428-430.

, Herrington, L. P., and Winslow, C.-E. A. (1937). Thermal interchanges between the human body and its atmospheric environment. American Journal of Hygiene, 26, 84-102.

- Stolwijk, J. A. J., and Hardy, J. D. (1967). Comfort and thermal sensations and associated physiological responses at various ambient temperatures. Environmental Research, 1, 1-20.

,-- , and Nishi, Y. (1969a). The prediction of thermal comfort when thermal equilibrium is maintained by sweating. ASHRAE Transactions, 75, part II, pp. 108-120. ,-- and $-(1971)$. An effective temperature scale based on a simple model of human physiological regulatory response. ASHRAE Transactions, 77, part I, pp. 247-262.

- , - and Saltin, B. (1969b). Comfort and thermal sensations and associated physiological responses during exercise at various ambient temperatures. Environmental Research, 2, 209-229.

Griffiths, I. D., and McIntyre, D. A. (1972a). Radiant heating and comfort. Building Services Engineer, 40, June, A32-A34.

, and - (1972b). Radiant temperature and comfort. Proceedings of CIB symposium on thermal comfort. Building Research Station, London, September.

Hardy, J. D., and Stolwijk, J. A. J. (1966). Partional calorimetric studies of man during exposures to thermal transients. Journal of Applied Physiology, 21, 1799-1806.

Hardy, James D. (1970). Skin temperature and physiological thermoregulation. In Physiological and Behavioral Temperature Regulation, edited by James D. Hardy, A. Pharo Gagge, and Jan A. J. Stolwijk, Chapter 57. Thomas, Springfield, Illinois.

Humphreys, M. A., and Nicol, J. F. (1970). An investigation into thermal comfort of office workers. Journal of the Institution of Heating and Ventilating Engineers, 38, 181-189.

Korsgaard, V., and Madsen, T. L. (1971). New instruments for measuring thermal comfort. Proceedings of the 13th International Congress of Refrigeration, Washington 
D.C., 1971. Vol. 4, pp. 313-322.

, (1973). Neue Geräte zur Behaglichkeitsmessung. Klima und Kälte Ingenieur. August.

Kerslake, D. McK. (1972). The Stress of Hot Environments. University Press, Cambridge. (Monographs of the Physiological Society, No. 29).

Leithead, C. S., and Lind, A. R. (1964). Heat Stress and Heat Disorders. Cassell, London.

McNall, P. E., Jr., and Biddison, R. E. (1970). Thermal and comfort sensations of sedentary persons exposed to asymmetric radiant fields. $A S H R A E$ Transactions, 76, Part I, pp. 123-136

- Jaax, J., Rohles, F. H., Nevins, R. G., and Springer, W. (1967). Thermal comfort (thermally neutral) conditions for three levels of activity. ASHRAE Transactions, 73, Part I, pp. I.3.1.-I.3.14 (No. 2014).

_, Ryan, P. W., and Jaax, J. (1968). Seasonal variation in comfort conditions for college-age persons in the Middle West. ASHRAE Transactions, 74, Part I, pp. IV.2.1-IV.2.9.

-, and Schlegel, J. C. (1968). The relative effects of convection and radiation heat transfer on thermal comfort (thermal neutrality) for sedentary and active human subjects. ASHRAE Transactions, 74, Part II, pp. 131-143.

Madsen, Th. Lund. (1972). Thermal environment parameters and their measurement. Proceedings of CIB symposium on thermal comfort. Building Research Station, London, September.

Missenard, A. (1957). Mise au point sur les échanges thermiques entre le corps humain et l'ambiance; coefficient de charge thermique dans les ambiances chaudes. Industries thermiques, 3, 735-752.

Nevins, R. G., Rohles, F. H., Springer, W., and Feyerherm, A. M. (1966). Temperature-humidity chart for thermal comfort of seated persons. ASHRAE Transactions, 72 , Part I, pp. 283-291.

Nicol, J. F., and Humphreys, M. A. (1972). Thermal comfort as part of a self-regulating system. Proceedings of $C I B$ symposium on thermal comfort. Building Research Station, London, September.

Nielsen, Marius (1947). Undersøgelser over relationen mellem behagelighedsfornemmelser, opvarmningstilstand og fysiologiske reaktioner ved stillesiddende arbejde. (Studies on the relation between sensations of comfort, degree of heating and physiological reactions). Boligopvarmningsudvalgets meddelelse, No. 3, København.

Olesen, S., Bassing, J. J., and Fanger, P. O. (1972a). Physiological comfort conditions at sixteen combinations of activity, clothing, air velocity and ambient temperature. ASHRAE Transactions, 78, Part II. pp. 199-206.

prefer a lower ambient temperature? In: 5th International Congress for Heating, Ventilating and Air-Conditioning, edited by H. Salmark, Copenhagen, 1971, Vol. I, pp. 27-40.

,-- Jensen, P. B., and Nielsen, O. J. (1972b). Comfort limits for man exposed to asymmetric thermal radiation. Proceedings of CIB symposium on thermal comfort. Building Research Station, London, September.

Östberg, O., and Nicholl, A. G. McK. (1973). The preferred thermal conditions for 'morning' and 'evening' types of subjects during day and night-preliminary results. BUILD International, 6, no. 1, pp. 147-157.

Rohles F. H., Jr., and Nevins, R. G. (1971). The nature of thermal comfort for sedentary man. ASHRAE Transactions, 77, Part I, pp. 239-247.

- , and Johnson, M. A. (1972). Thermal comfort in the elderly. ASHRAE Transactions, 78, Part I, pp. 131-137. , Woods, J. E., and Nevins, R. G. (1973). The influence of clothing and temperature on sedentary comfort. ASHRAE Transactions, 79, Part I. In press.

Stolwijk, J. A. J., and Hardy, J. D. (1966). Partional calorimetric studies of responses of man to thermal transients. Journal of Applied Physiology, 21, 967-977.

Winslow, C.-E. A., Herrington, L. P., and Gagge, A. P (1937). Relations between atmospheric conditions, physiological reactions and sensations of pleasantness. American Journal of Hygiene, 26, 103-115.

Wyon, D. P., Asgeirsdóttir, Bóra, Kjerulf-Jensen, P., and Fanger, P. O. (1973). The effects of ambient temperature swings on comfort, performance and behaviour. Proceedings of symposium on "Quantitative prediction of the physiological and psychological effects of the thermal environment on man', Centre d'Etudes Bioclimatiques, Strasbourg, July.

-, Lidwell, O. M., and Williams, R. E. O. (1968). Thermal comfort during surgical operations. Journal of Hygiene, 66, 229-248.

Yaglou, C. P. (1927). The comfort zone for men at rest and stripped to the waist. Transactions of the American Society of Heating and Ventilating Engineers, 33, 165-179.

Received for publication June 18, 1973

Accepted for publication July 4, 1973 